\title{
Comparisons of day-time and night-time hydroacoustic surveys in temperate lakes
}

\author{
Michaël Girard ${ }^{1}$, Chloé Goulon ${ }^{1}$, Anne Tessier ${ }^{1,3}$, Pascal Vonlanthen ${ }^{2,4}$ and Jean Guillard ${ }^{1, *}$ \\ ${ }^{1}$ Univ. Savoie Mont Blanc, INRAE, CARRTEL, 74200 Thonon-les-Bains, France \\ 2 Department of Fish Ecology and Evolution, Centre of Ecology, Evolution and Biogeochemistry, EAWAG Swiss Federal Institute \\ of Aquatic Science and Technology, Seestrasse 79, 6047 Kastanienbaum, Switzerland \\ ${ }^{3}$ Marepolis, 43 rue Louis Blanc, 11210 Port-La-Nouvelle, France \\ 4 Aquabios Sàrl/GmbH, Les Fermes 57, 1792 Cordast, Switzerland
}

Received 2 December 2019 / Accepted 16 July 2020

Handling Editor: Verena Trenkel

\begin{abstract}
In recent years, due to an increased need for non-intrusive sampling techniques, hydroacoustics has attracted attention in fishery science and management. Efforts to promote standardisation are increasing the accuracy, efficiency, and comparability of this method. The European Water Framework Directive and the Standard Operating Procedures for Fisheries Hydroacoustic Surveys in North American Great Lakes has recommended that surveys be conducted at night. At night, fish usually disperse in the water column, thus allowing for single echo detection and subsequent accurate fish size estimation, while day-time schooling behaviour hampers the estimation of fish size. However, sampling during the day would often be safer and cheaper. This study analyses how fisheries hydroacoustic results differ between day-time and night-time surveys, using data from 14 natural temperate lakes of various size. Data collected during the day and night at two depth layers linked to thermal stratification were compared in terms of acoustic scattering strength, target strength, and biomass estimates. The results showed a significant correlation between day-time and night-time estimates, though biomass in the upper layer was biased for day-time surveys, mainly due to incorrect fish size estimates resulting from rare single echo detections and schooling behaviour. Biomass estimates for the lower depth layer did not significantly differ between the two diel periods. Thus, this study confirms that hydroacoustic sampling in temperate lakes should be performed at night for accurate fish stock biomass estimates.
\end{abstract}

Keywords: Fish stock / diel migration / lake / standardisation / behaviour

\section{Introduction}

Hydroacoustics is now a recognised method (Draštík et al., 2017) for estimating the abundance and biomass of freshwater fish populations (Pollom and Rose, 2016), especially in lakes. Recent studies have shown a good relationship between biomass estimates obtained by hydroacoustics (see description in Simmonds and MacLennan, 2005) and common standard benthic gillnets described in CEN (2005) (Emmrich et al., 2012; Yule et al., 2013). Hydroacoustics must be complemented with additional sampling (e.g., gillnetting or trawling) (Kubečka et al., 2009; DuFour et al., 2019) to obtain species composition, individual fish characteristics (e.g., length and weight), and biological samples (scales, flesh, and stomachs).

\footnotetext{
*Corresponding author: jean.guillard@inrae.fr
}

Hydroacoustics has been standardised in Europe (CEN, 2009) and in North America (Parker-Stetter et al., 2009). Compared to other fishery-independent methods, such as gillnetting and trawling, its main advantage is non-intrusive sampling of fish populations (Simmonds and MacLennan, 2005) and the capability of stock estimation at large scales in natural lakes (Wheeland and Rose, 2014; Morrissey-McCaffrey et al., 2018), and in reservoirs (Godlewska et al., 2016; Guo et al., 2019; Tessier et al., 2020).

Like other sampling methods, hydroacoustics has inherent biases and limitations regarding fish species discrimination, blind zones (areas close to the surface or near the lake bottom), individual variability (individual size measurements are highly variable), and varying accessibility due to fish behaviour (e.g., very shallow waters, dense macrophyte areas) (Rudstam et al., 2012). Thus, fish behaviour must be considered when defining the best survey period, with species-specific behaviour and 


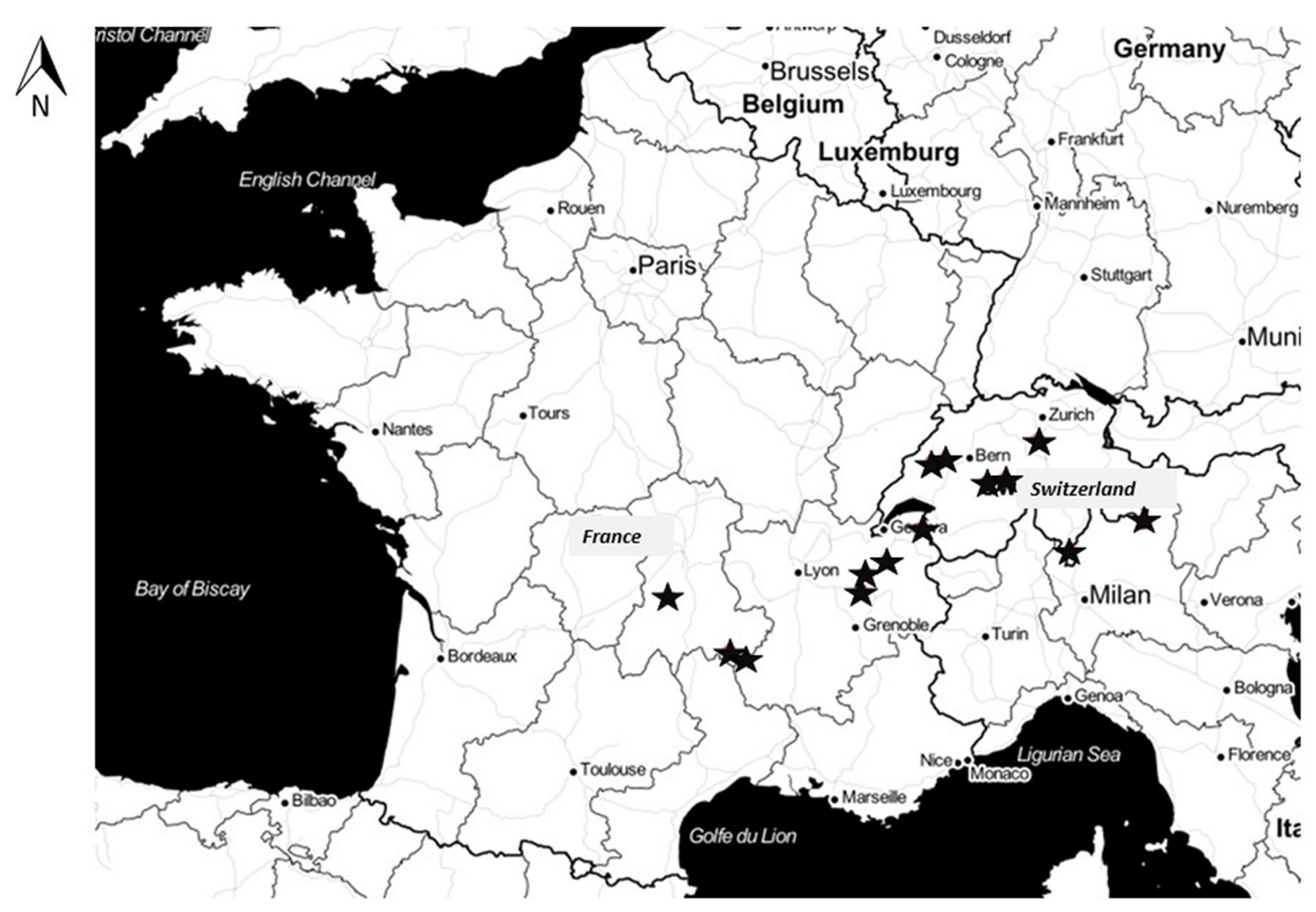

Fig. 1. Geographical location (stars) of the 14 studied lakes distributed in France and Switzerland.

spatial distributions adding uncertainty to hydroacoustic estimates. Furthermore, fish species diversity implies a high variability of behaviours and movements, according to biotic and abiotic factors (Matthews, 2012). Fish perform vertical and horizontal migrations depending on abiotic factors, such as temperature, luminosity (day, night, and lunar cycle), and turbidity, and on biotic factors such as life stage (adults, juveniles, and larvae), species interactions (e.g., prey-predator and competition), and resources (Bohl, 1979; Mehner, 2012; Sajdlová et al., 2018). Therefore, the choice of the sampling period (e.g., season and time of day) is important as it can greatly affect hydroacoustic results.

In temperate freshwater ecosystems, standard procedures (CEN, 2009; Parker-Stetter et al., 2009) recommend sampling during the night at the end of the summer, when thermal stratification separates fish species (Brandt et al., 1980; Mehner, 2012; Anderson et al., 2019). During the day-time, many species form schools, stay in littoral zones, or remain near the lake bottom (Bohl, 1979; Gliwicz et al., 2006; Ríha et al., 2014). As a result, during day-time surveys, the estimation of fish size is usually difficult, leading to biased estimates (Appenzeller and Leggett, 1992). At dusk, schools disperse to locate food or optimal temperatures in the pelagic zone (Bohl, 1979; Mehner et al., 2010), facilitating night-time detection of single echoes, accurate target strength (TS) measurements, and thus representative fish size distributions (Rudstam et al., 2012).
However, night-time sampling is often more expensive, especially due to increased staff costs linked to labour-related legislation. Furthermore, it is also less safe on the small boats usually used during freshwater surveys (risk of falling asleep, risk of collision with obstacles), and especially in reservoirs, where submerged trees are frequently encountered (Coll et al., 2007; Tessier et al., 2020). While many studies have already described day-time to night-time hydroacoustic survey results (Vondracek and Degan, 1995; Guillard and Vergés, 2007; Ye et al., 2013), this study is the first, to the best of our knowledge, to compare hydroacoustic day-time and night-time data from 14 different temperate natural lakes. In this study, we compared a proxy of fish density, mean acoustic scattering strength ( $s A$ with units $\mathrm{m}^{2} \mathrm{ha}^{-1}$ ) (MacLennan et al., 2002; Yule et al., 2013), and a proxy of fish size, mean target strength (TS with units dB) (MacLennan et al., 2002), between day and night samplings. Biomass estimates computed from these two metrics were analysed to identify differences and verify if night-time is the most appropriate sampling period, as described in the literature and standards.

\section{Materials and methods}

\subsection{Study sites}

We sampled 14 natural temperate lakes in France and Switzerland (Fig. 1). The lakes have different trophic statuses, 
Table 1. Characteristics of the 14 studied lakes. DoC: degree of coverage of acoustics surveys at day-time and night-time.

\begin{tabular}{|c|c|c|c|c|c|c|c|c|}
\hline Lake & Survey date & $\begin{array}{l}\text { Thermocline } \\
\text { depth }(\mathrm{m})\end{array}$ & $\begin{array}{l}\text { Maximum } \\
\text { depth (m) }\end{array}$ & $\begin{array}{l}\text { Altitude } \\
\text { (m) }\end{array}$ & $\begin{array}{l}\text { Surface } \\
\left(\mathrm{km}^{2}\right)\end{array}$ & Trophic status & $\begin{array}{l}\text { DoC } \\
\text { day }\end{array}$ & $\begin{array}{l}\text { DoC } \\
\text { night }\end{array}$ \\
\hline \multicolumn{9}{|l|}{ France } \\
\hline Annecy & $17 / 09 / 2012$ & 13 & 65 & 447 & 27.59 & Oligotrophic & 8.7 & 8.9 \\
\hline Bouchet & $15 / 09 / 2005$ & 11 & 27 & 1200 & 0.44 & Oligotrophic & 5.4 & 6.2 \\
\hline Bourget & $01-02 / 10 / 2012$ & 15 & 147 & 231 & 44.5 & Oligo-mesotrophic & 13.9 & 13.7 \\
\hline Montriond & $28 / 09 / 2006$ & 6 & 15 & 1055 & 0.32 & Mesotrophic & 7.7 & 5.8 \\
\hline Pavin & $22 / 09 / 2005$ & 10 & 93 & 1197 & 0.44 & Oligo-mesotrophic & 9.4 & 9.0 \\
\hline \multicolumn{9}{|l|}{ Switzerland } \\
\hline Brienz & $13-14 / 09 / 2011$ & 20 & 260 & 564 & 29.8 & Ultra-oligotrophic & 9.3 & 13.3 \\
\hline Lugano & $18-19 / 10 / 2011$ & 10 & 288 & 271 & 48.7 & Eutrophic & 8.0 & 10.4 \\
\hline Morat & $11 / 10 / 2010$ & 15 & 45 & 429 & 22.8 & Meso-eutrophic & 8.0 & 10.2 \\
\hline
\end{tabular}

ranging from ultra-oligotrophic to eutrophic, are of various shape and size $\left(0.32\right.$ to $\left.218.3 \mathrm{~km}^{2}\right)$, and include shallow and deeper lakes (maximum depth 15 to $288 \mathrm{~m}$ ) (Tab. 1).

Temperature profiles were determined at the maximum depth of each lake using a multi-parameter probe the same week the hydroacoustic surveys were carried out. All lakes were thermally stratified at the sampling time (DeceliereVergès, 2010; Périat, 2012; Périat and Vonlanthen, 2013; Vonlanthen and Périat, 2013). Fish communities, which were sampled by gillnetting according to the European standard procedure (CEN, 2005), were mainly dominated by Cyprinidae, Percidae, and Salmonidae (Deceliere-Vergès, 2010; Périat, 2012; Périat and Vonlanthen, 2013; Vonlanthen and Périat, 2013).

\subsection{Surveys}

Hydroacoustic surveys were carried out using a Simrad EK60 echosounder (Simrad Kongsberg Maritime AS, Horten, Norway) operating at a frequency of $70 \mathrm{kHz}$, with a pulse length of $0.256 \mathrm{~ms}$ (Godlewska et al., 2011). The power was fixed at $100 \mathrm{~W}$, and the sampling intervals were set at 5 pulses $\mathrm{s}^{-1}$. The split-beam transducer has a half-power beam angle of $11^{\circ}$ at $-3 \mathrm{~dB}$, transmitted vertically, and was positioned at a depth of $0.5 \mathrm{~m}$ below the water surface. Calibrations were performed before the surveys according to the procedure reported by Foote et al. (1987) and recommended by the manufacturer. Data were collected according to the standard protocol for hydroacoustics in Europe (CEN, 2009), during calm to moderate wind conditions, $1 \mathrm{~h}$ after sunset for the night survey at a mean speed of $8 \mathrm{~km} \mathrm{~h}^{-1}$. Data were georeferenced using a global positioning system (GPS). The survey design, a series of equally spaced parallel transects, covering areas with depths $>5 \mathrm{~m}$, was similar between day-time and night-time, but due to logistic reasons, the tracks were not strictly identical between the two periods. The sampling effort was computed by calculating the degree of coverage, which is defined as the ratio between the sampling distance travelled $(\mathrm{km})$ and the square root of the lake surface area $\left(\mathrm{km}^{2}\right)$ (Aglen et al., 1983). As a general recommendation, the degree of coverage should be at least 3.0 and preferably near or above 6.0. (Emmrich et al., 2012). All studied lakes had a minimum degree of coverage greater than 4.9 , being mainly above 6 (Tab. 1 ). The acoustic data recording was limited to the first $100 \mathrm{~m}$ because fish are scarce at greater depths in these type of lakes (Yule et al., 2013).

For analysis, the water column was split into two layers according to the separation of fish assemblages by temperature (Mehner et al., 2010). The upper layer extended from $3 \mathrm{~m}$ below the lake surface to avoid the acoustic near field, where backscattering measurements are unreliable, to the thermocline depth. The lower layer started at the thermocline and extended to $0.3 \mathrm{~m}$ above the lake bottom.

\subsection{Hydroacoustic data}

For each lake, all hydroacoustic transects were merged into a single file and analysed using a whole-lake approach following Emmrich et al. (2012). This approach overcame the issue of the non-matching day- and night-time transects. Mean acoustic scattering strength $\left(s A\right.$ in $\left.\mathrm{m}^{2} \mathrm{ha}^{-1}\right)$ and mean target strength (TS in $\mathrm{dB}$ ), calculated in the linear domain, were computed for both depth layers. TS was converted into the fish length in centimetres (total length $=\mathrm{TL}$ ) by inversing Love's (1971) equation:

$$
\mathrm{TS}=19.1 \log _{10}(T L)-0.9 \log _{10}(70)-62 .
$$

This equation was used because it was derived from several species assemblages with a large range of species and sizes, and is still commonly used and relevant (MacNamara et al., 2016; DuFour et al., 2017; Zenone et al., 2017), especially for freshwater ecosystems (Emmrich et al., 2012; Draštík et al., 2017; Morrissey-McCaffrey et al., 2018). 
Table 2. Hydroacoustic survey results. Estimated mean $S A$, mean TS, and biomass from day-time and night-time surveys by lake and depth layer.

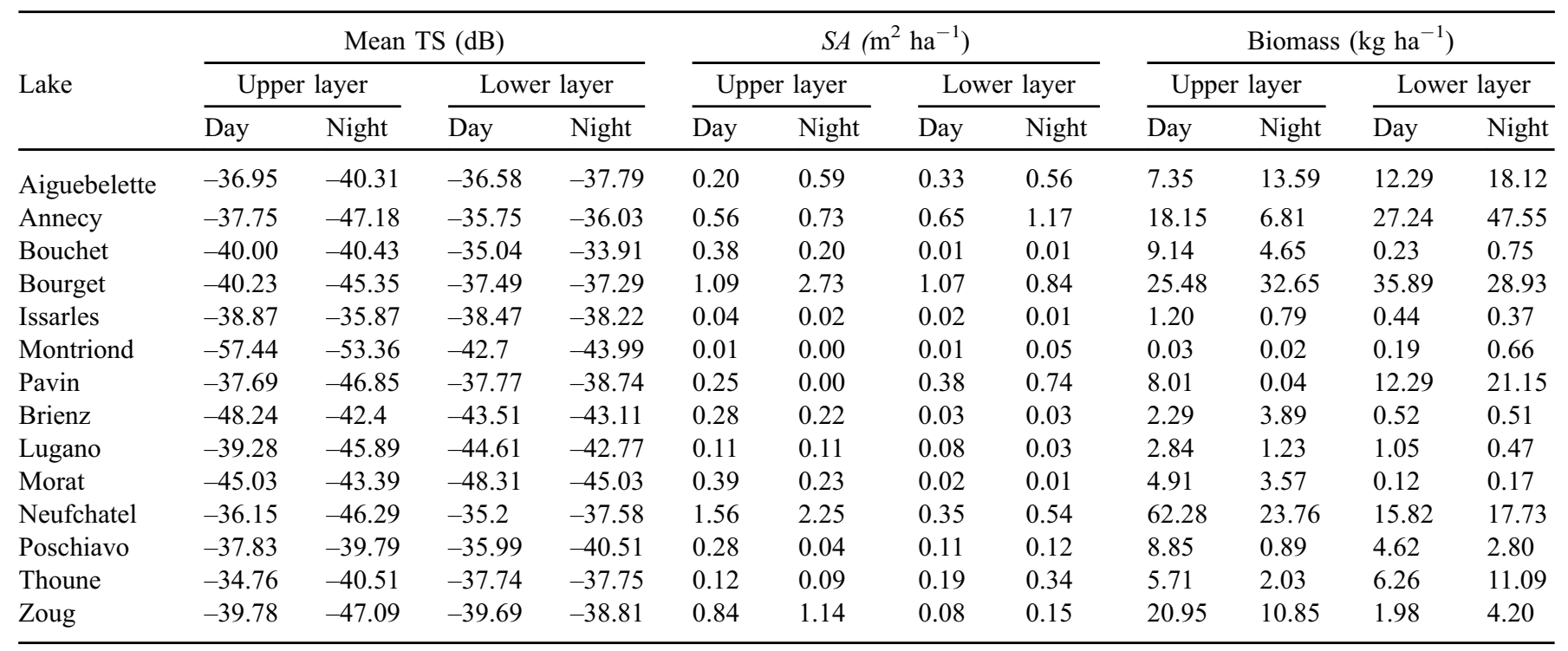

Fish density $\left(\rho_{a}\right)$ per ha was estimated using Forbes and Nakken's (1972) equation:

$$
\rho_{a}=\frac{\boldsymbol{s} \boldsymbol{A}}{4 \pi^{*} 10^{\mathrm{TS} / 10}} .
$$

Average individual fish weight $\bar{w}(\mathrm{~kg})$ was calculated from individual sizes based on Carlander's (1969) equation $\left(w=\mathrm{TL}^{3}\right)$. Then, fish biomass $B\left(\mathrm{~kg} \mathrm{ha}^{-1}\right)$ was calculated by multiplying mean fish density by average fish weight:

$$
B=\bar{\rho} \bar{w}
$$

\subsection{Data analysis}

Data were analysed using the Sonar 5-Pro software (version 6.0.4) (Balk and Lindem, 2011). Lake bottoms were automatically detected by the software and then manually corrected. An exclusion zone of $0.3 \mathrm{~m}$ above the bottom was used to avoid false echoes from the bottom. Non-fish echoes from air bubbles, macrophytes, secondary bottom echo detections, and similar were manually removed. Furthermore, data from the surface to $3 \mathrm{~m}$ were removed to avoid surface noise and data from the near-field (Draštík et al., 2017). TS thresholds were set to $-60 \mathrm{~dB}$ to include juvenile fish [i.e., greater than $\sim 2 \mathrm{~cm}$ in total length, based on equation (1)] and the threshold of area backscattering strength was set $6 \mathrm{~dB}$ lower, at $-66 \mathrm{~dB}$, according to Parker-Stetter et al. (2009). Single echoes were detected using the following settings: a pulse length ratio between 0.8 and 1.3 , a maximum gain compensation of $3 \mathrm{~dB}$ (one way), and a sample angle standard deviation of 0.3 degrees (Godlewska et al., 2011; Guillard et al., 2004). In previous analyses (Girard, 2018), the number of single echo detections was checked for elementary sampling units of $250 \mathrm{~m}$ in accordance with the Sawada index $N v$ (the number of fish per hydroacoustic volume sampled)
(Sawada et al., 1993), as recommended in the hydroacoustic standards (CEN, 2009). When the index is greater than 0.1 , the results should be analysed with caution (CEN, 2009), but no result exceeded this threshold in the surveys (Girard, 2018).

\subsection{Statistical analysis}

We analysed differences between mean $\boldsymbol{s} \boldsymbol{A}$, mean TS, and biomass estimated during day-time and night-time hydroacoustic surveys using paired Student's t-tests or nonparametric Wilcoxon tests. Parametric Pearson or nonparametric Spearman correlation tests were used to test the correlation between the estimates from the two periods. Non-parametric tests were used when the homogeneity or normality of the data was not achieved. Furthermore, a standardised main axis (SMA) test was performed according to Warton et al. (2006). This test has previously been used to compare hydroacoustics data from two different situations (Godlewska et al., 2011; Mouget et al., 2019). This procedure is appropriate to enhance and complete linear regression, and when measurement error is unknown (Warton et al., 2006), which is the case for acoustic metrics. The SMA evaluates whether the major-axis regression results for the comparison of day-time and night-time periods follow a 1:1 line, which would indicate no difference. In other words, it tests the null hypothesis of intercept zero and slope 1 of a linear relationship. All analyses were carried out using software R, version 3.4.3 (R Core Team, 2014) and the Smatr package (version 3.4-8; Warton et al., 2012) for the SMA test.

\section{Results}

Results for the three metrics, $s A$, TS, and biomass are shown by lake in Table 2. Acoustic scattering strength $s A$ in the upper depth layer did not significantly differ between day-time and night-time surveys for the 14 lakes (Wilcoxon test, 

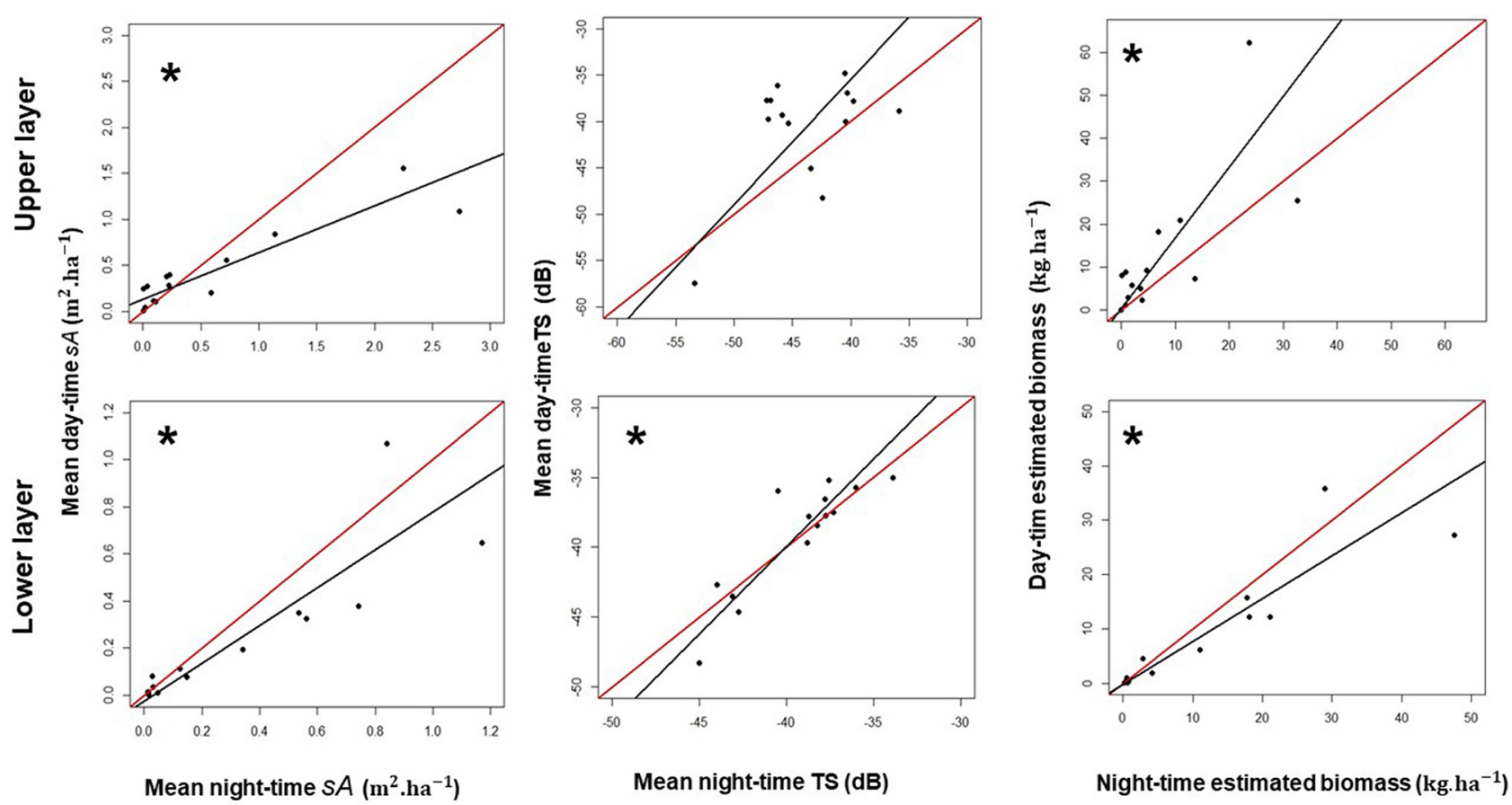

Fig. 2. Linear relationship between day and night results for upper (A) and lower (B) depth layers in 14 temperate lakes. A star indicates significant correlations $(p<0.05)$. The red line represents the 1:1 line, and the black line the relationship estimated by the SMA $(N=14)$.

Table 3. Summary of statistical tests $(p<0.05)$ comparing results for day-time and night-time surveys. Wilcoxon or Student tests were used to test for differences in means. Pearson or Spearman tests for testing correlations and standardised mean axis (SMA) tests for testing linear relationships (null hypothesis: intercept 0 and slope 1 ).

\begin{tabular}{llll}
\hline Variable & & Upper layer & Lower layer \\
\hline \multirow{3}{*}{$s A\left(\mathrm{~m}^{2} \mathrm{ha}^{-1}\right)$} & Mean values & No difference & No difference \\
& Correlation & Yes & Yes \\
& SMA & Yes & No \\
TS (dB) & Mean values & Difference & No difference \\
& Correlation & No & Yes \\
& SMA & No & No \\
Biomass $\left(\mathrm{kg} \mathrm{ha}^{-1}\right)$ & Mean values & Difference & No difference \\
& Correlation & Yes & Yes \\
& SMA & Yes & No \\
\hline
\end{tabular}

$p=0.76$ ) and mean values from the two periods were significantly correlated (Spearman's $r=0.84 ; p<0.001$ ). However, the slope of the linear relationship was significantly lower than 1 (SMA $r=-0.87, p<0.0001$ ), while the intercept was not significantly different from 0 (SMA intercept $=2.13$, $p=0.055$ ) (Tab. 3 and Fig. 2). This means lakes with larger mean $s A$ had lower day-night differences in absolute terms. Similar results were found for the lower depth layer except that the slope in the SMA was not significantly different from 1 (Student $t=-1.84$. $p=0.089$; Pearson's $r=0.87 . p<0.0001$; SMA $r=-0.40 . p=0.15$; SMA intercept $=-0.50 . p=0.63$ ) (Tab. 3 and Fig. 2).
The mean number of single echoes detected in the upper depth layer was lower during the day than at night, though this did not reach statistical significance (Wilcoxon test, $p=0.119$ ), while for the lower depth layer, the mean number of single echoes was significantly lower during day-time in most lakes (Wilcoxon test, $p=0.0067$ ) (Fig. 3).

Regarding mean TS, for the upper depth layer, a significant difference between day and night values was observed (Student $t=2.25, p=0.04$ ), with higher values during daytime in most lakes (Tab. 3 and Fig. 2). No significant correlation was found (Pearson's $r=0.50, p=0.07$ ), though the SMA slope was not significantly different from 1 (SMA $r=0.33, p=0.24$ ) and the intercept was not significantly different from 0 (SMA intercept $=1.25, p=0.23)$. In contrast, for the lower depth layer, no significant difference was found between day-time and night-time mean TS values (Student $t=0.38, p=0.71$ ), and the correlation between the results from the two periods was significant (Pearson's $r=0.89, p<$ 0.0001). Similarly, neither the observed SMA slope nor the intercept was significantly different from the null hypothesis (SMA $r=0.45, p=0.11$; SMA intercept $=1.56, p=0.15)$. The mean value across lakes of the absolute difference between day-time and night-time TS values was more than $5 \mathrm{~dB}$ for the upper depth layer and close to $1 \mathrm{~dB}$ for the lower depth layer.

The biomass in the upper depth layer differed significantly between day and night-time (Wilcoxon, $p=0.049$ ). Despite this, mean values were significantly correlated (Spearman's $r=0.73, p=0.004$ ) (Tab. 3 and Fig. 2). Biomass were higher at in the day in $78 \%$ of the lakes. A significant difference was detected between the observed slope and 1 (SMA $r=0.61$, $p=0.02$ ), but no difference in intercept was found (SMA intercept $=0.08, p=0.94)$. Again, for the lower depth layer, 


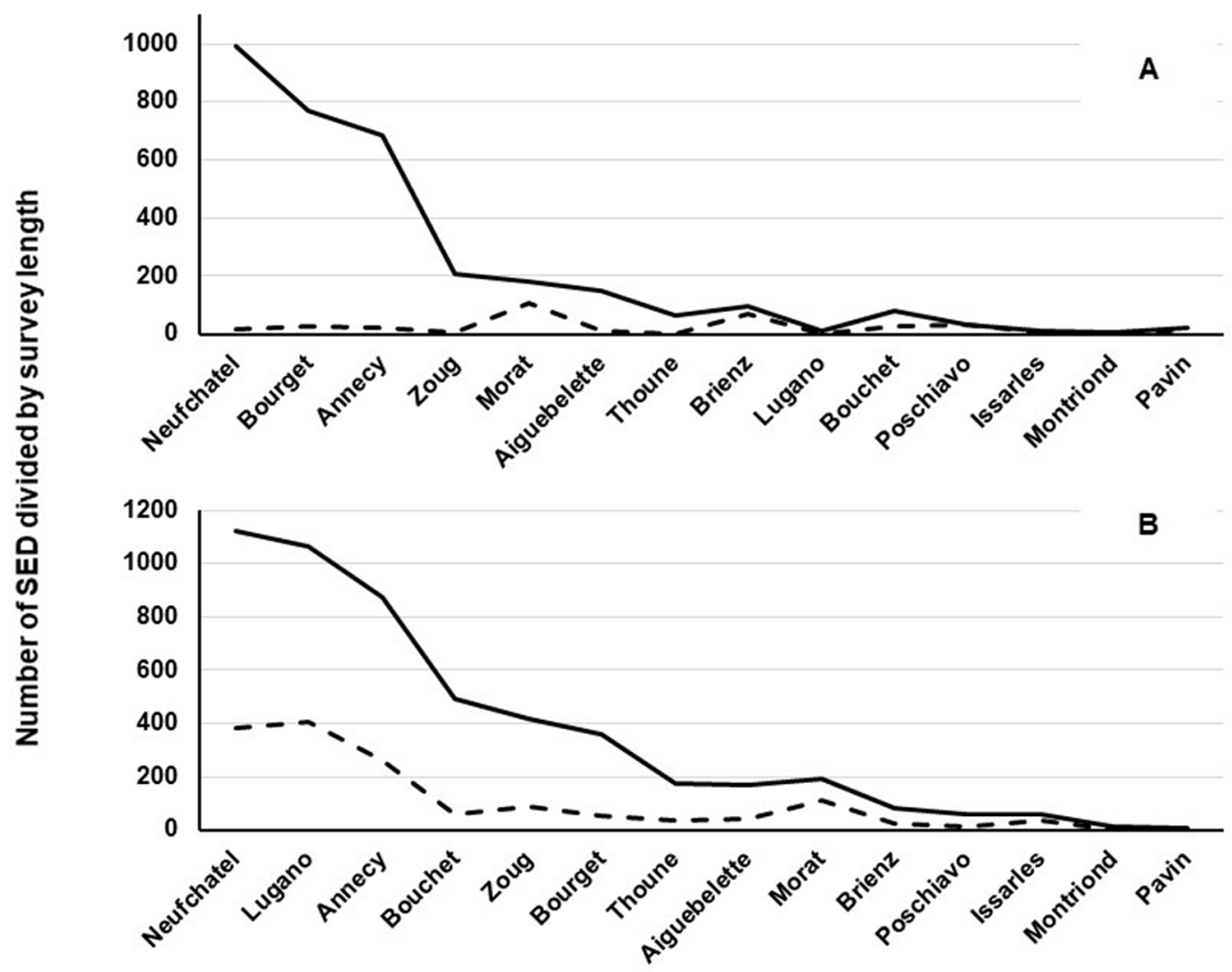

Fig. 3. Number of single echo detections (SED) by survey, weighted by survey length in $\mathrm{km}$. Lakes are sorted by decreasing night-time SED: (A) upper depth layer; (B) lower depth layer. Solid line night-time results; dashed line day-time results.

there was no significant difference between day-time and night-time estimated biomass (Wilcoxon, $p=0.15$ ). Values were significantly correlated (Spearman's $r=0.90, p<0.0001$ ) and neither the slope nor the intercept differed from the expected value (SMA intercept $=-0.49, p=0.08$; SMA $r=-0.12, p=0.91)$.

\section{Discussion}

Hydroacoustics provide accurate estimates of fish stock biomass in lakes, but the results depend on fish behaviours which must be considered when defining the best survey period (Rudstam et al., 2012). In temperate lakes, fish assemblages are mainly dominated by Percidae and Cyprinidae and, to a lesser extent, by Salmonidae. These assemblages are not evenly distributed in the water column due to thermal stratification during the survey season in late summer/early autumn. In the upper depth layers perch (Perca fluviatilis) and roach (Rutilus rutilus) are usually dominant, with frequently high densities of juveniles (Masson et al., 2001; Guillard et al., 2006a). At this time of the year in natural lakes, these species are far enough from the surface to avoid underestimation using hydroacoustics (Guillard et al., 2006b; Emmrich et al., 2012). In the deeper and colder depth layers, Salmonidae (Coregonus spp. and Salvelinus spp.) are the dominant species (Dembiński, 1971; Probst et al., 2009; Mehner et al., 2010), while density depends on the lake's trophic status (Gerdeaux et al., 2006).
Similar to previous studies (Appenzeller and Leggett, 1992; Draštík et al., 2009; Ye et al., 2013), we found that the diel survey period affected hydroacoustic measurements in 14 temperate natural lakes.

In the upper depth layer, day-time and night-time estimates were significantly correlated across lakes, except for mean TS values. For $s A$, the differences between day and night values were not significant, but correlation and SMA tests highlighted that differences occurred between the two periods. Not surprisingly, significant diel differences were found for biomass estimates. These differences were due to differences in TS estimates linked to fish aggregation behaviour and a smaller number of single echoes detected during the day-time. Day-time biomass were higher than night-time results for most lakes. Juvenile fish in warmer water layers form schools (Appenzeller and Leggett, 1992; Probst et al., 2009; Ye et al., 2013) and this behaviour impacts hydroacoustic results during the day-time. Schooling creates hydroacoustic shadowing and prevents the reliable detection of individuals, thus hampering accurate size estimation (Probst et al., 2009; Rudstam et al., 2012). Furthermore, there is a higher probability of obtaining TS from non-individual fish (two or more fish in the same volume considered as one fish). As a result, the mean TS is overestimated, leading to overestimated average individual fish size (Bohl, 1979; Fréon and Misund, 1998; Axenrot et al., 2004). Furthermore, as the number of single echo detections is limited, the estimated size distribution is imprecise. As a consequence, sampling during the day-time in the upper depth 
layer of temperate lakes led to biased size metrics and overestimated biomass, which was confirmed by this study.

Considering the lower depth layer, data for day-time and night-time were significantly correlated, and no significant differences were observed for any metrics. In contrast to the upper depth layer, no fish aggregations were observed in our study below the thermocline, although whitefish (Coregonus $s p$.), the main Salmonidae species in the sampled lakes, sometimes aggregate (Kahilainen et al., 2004) or form shoals (Shaw, 1962; Mehner, 2012). Coregonids usually migrate to the upper part of this depth layer at night and return to deeper water during the day-time (Swales, 2006), but such behaviours do not impact the results.

Draštík et al. (2009) have also discussed detection differences between day and night, but only for European reservoirs. These authors highlighted the issues related to the formation of fish schools and the horizontal and vertical movements between day and night. However, other explanations cannot be totally excluded, such as boat avoidance, which also biases TS estimates (Fréon et al., 1993) and, therefore, affects biomass estimates. Vessel noise can affect abundance and biomass estimates (Wheeland and Rose, 2015; DuFour et al., 2018), but should not lead to differences between day and night. However, as higher traffic usually occurs in the day-time, this could nevertheless increase the difference between the two sampling periods (Godlewska, 2002). Lake specific parameters (refuge sites, predators) could also influence abundance and biomass (Bohl, 1979; Gliwicz et al., 2006). The presence of predators could modify schooling behaviour (Eklöv and VanKooten, 2001; Jacobsen et al., 2004; Hölker et al., 2007), thus affecting estimates. In the presence of a predator, the prey will hide among the vegetation, where acoustic detection is not possible (Christensen and Persson, 1993; Persson and Eklöv, 1995). Acoustic detection problems for day-time sampling could be mainly due to the need to feed and seek protection from predation (Godlewska, 2002; Snickars et al., 2004). In the same way, light conditions (moon phase and artificial lights) can affect population estimates of pelagic fish in lakes (Luecke and Wurtsbaugh, 1993). Fish behaviour involves complex mechanisms due to multiple parameters, and it is difficult to identify the most important ones (Brehmer et al., 2019).

In summary, fish behaviour biases hydroacoustic estimates, and this study - using data from 14 natural temperate lakes confirms that hydroacoustic sampling should be performed at night-time to obtain accurate estimates, as recommended by standards and the literature. Nevertheless, in the lower depth layer of temperate lakes, where Salmonidae are dominant, behaviours such as schooling and migration are less pronounced. Hence, the lower depth layer can be sampled during day-time without affecting acoustic biomass estimates.

Acknowledgements. This work was supported by Pole ECLA (ECologie LAcustre) from the OFB (Office Français de la Biodiversité), AnaEE-France, and the OLA Observatory (DOI: 10.4081/jlimnol.2020.1944) provided boat and technical facilities. Part of the data came from the "Projet Lac" led by Prof. Ole Seehausen (EAWAG and the University of Berne), as well as cantonal authorities and FOEN for funding. We want to thank the anonymous referees for their very helpful comments, which greatly improved the manuscript.

\section{References}

Aglen A, Nakken O, Venema SC. 1983. Random errors of hydroacoustic fish abundance estimates in relation to the survey grid density applied, in: O. Nakken, S.C. Venema (Eds.). Fisheries Hydroacoustics Symposium. FAO Fish. Rep. 300. Bergen. Norway. 21-24 June 1982, 1983, pp. 293-298.

Anderson R, Hobbs B, Koonce J, Locci A. 2019. Modeling hydrology - habitat fish population linkages for Lake Erie. Department of Geography and Environmental Engineering 313 Ames Hall. The Johns Hopkins University. 19 p.

Appenzeller AR, Leggett WC. 1992. Bias in hydroacoustic estimates of fish abundance due to hydroacoustic shadowing: evidence from day-night surveys of vertically migrating fish. Can J Fish Aqua Sci 49: 2179-2189.

Axenrot T, Didrikas T, Danielsson C, Hansson S. 2004. Diel patterns in pelagic fish behaviour and distribution observed from a stationary, bottom-mounted, and upward-facing transducer. ICES J Mar Sci 61: 1100-1104.

Balk H, Lindem T. 2011. Sonar4 and Sonar5-Pro post processing systems. Operator manual version 6.01. Oslo: Lindem Data Acquisition.

Bohl E. 1979. Diel pattern of pelagic distribution and feeding in planktivorous fish. Oecologia 44: 368-375.

Brandt SB, Magnuson JJ, Crowder LB. 1980. Thermal habitat partitioning by fishes in Lake Michigan. Can J Fish Aquat Sci 37: 1557-1564.

Brehmer P, Sarré A, Guennégan Y, Guillard J. 2019. Vessel avoidance response: a complex tradeoff between fish multisensory integration and environmental variables. Rev Fish Sci Aqua 27: 380-391.

Carlander KD. 1969. Handbook of Freshwater Fishery Biology. Ames: Iowa State University Press.

CEN (European Committee for Standardization). 2005. EN 14757. Water quality - sampling of fish with multi-mesh gillnets. Brussels: CEN.

CEN (European Committee for Standardization). 2009. EN 15910. Water quality - Guidance on the estimation of fish abundance with mobile hydroacoustic methods. Brussels: CEN.

Christensen B, Persson L. 1993. Species-specific antipredatory behaviours: effects on prey choice in different habitats. Beh Ecol Sociol 32: 1-9.

Coll C, De Morais LT, Laë R, Lebourges-Dhaussy A, Simier M, Guillard J, Josse E, Ecoutin JM, Albaret JJ, Raffray J, Kantoussan J. 2007. Use and limits of three methods for assessing fish size spectra and fish abundance in two tropical man-made lakes. Fish Res 83: 306-318.

Deceliere-Vergès C. 2010. Caractérisation des métriques issues de l'échantillonnage de l'ichtyofaune lacustre et conséquences pour l'évaluation de la qualité du milieu. Doctorat Université de Savoie. https://prodinra.inra.fr/record/175110

Dembiński W. 1971. Vertical distribution of vendace Coregonus albula L. and other pelagic fish species in some Polish lakes. $J$ Fish Biol 3: 341-357.

Draštík V, Kubečka J, Čech M, Frouzová J, Ríha M, Juza T, Mrkvička T. 2009. Hydroacoustic estimates of fish stocks in temperate reservoirs: day or night surveys? Aquat Living Resour 22: 69-77.

DuFour MR, Mayer CM, Kocovsky PM, Qian SS, Warner DM, Kraus RT, Vandergoot CS. 2017. Sparse targets in hydroacoustic surveys: balancing quantity and quality of in situ target strength data. Fish Res 188: 173-182.

DuFour MR, Mayer CM, Qian SS, Vandergoot CS, Kraus RT, Kocovsky PM, Warner DM. 2018. Inferred fish behavior its 
implications for hydroacoustic surveys in nearshore habitats. Fish Res 199: 63-75.

DuFour MR, Qian Song S, Mayer CM, Vandergoot CS. 2019. Evaluating catchability in a large-scale gillnet survey using hydroacoustics: making the case for coupled surveys. Fish Res 211: 309-318.

Draštík V, Godlewska M, Balk H, Clabburn P, Kubečka J, Morrissey E, Hateley J, Winfield IJ, Mrkvička T, Guillard J. 2017. Fish hydroacoustic survey standardisation: a step forward based on comparisons of methods and systems from vertical surveys of a large deep lake. Limno Ocean Methods 15: 836-846.

Eklöv P, VanKooten T. 2001. Facilitation among piscivorous predators: effects of prey habitat use. Ecology 82: 2486-2494.

Emmrich M, Winfield IJ, Guillard J, Rustadbakken A, Vergès C, Volta P, Mehner T. 2012. Strong correspondence between gillnet catch per unit effort and hydroacoustically derived fish biomass in stratified lakes: comparison of gillnet catches with fish biomass estimates derived from hydroacoustics. Freshwater Biol 57: 2436-2448.

Foote KJ, Knutsen H, Vestnes G, MacLennan DN, Simmonds EJ. 1987. Calibration of hydroacoustic instruments for fish density estimation. Coop Res Rep Inter Coun Expl Sea 144: 1-70.

Forbes ST, Nakken O. 1972. Manual methods for fisheries resource survey and appraisal. Part I: the use of acoustic instruments for fish detection and abundance estimation. FAO Man Fish Ser 5: 138 p.

Fréon P, Misund OA. 1998. Dynamics of pelagic fish distribution and behaviour: effects on fisheries and stock assessment (1st ed.) Oxford: Wiley-Blackwell.

Fréon P, Soria M, Mullon C, Gerlotto F. 1993. Diurnal variation in fish density estimate during hydroacoustic surveys in relation to spatial distribution and avoidance reaction. Aquat Living Resour 6: 221-234.

Gerdeaux D, Anneville O, Hefti D. 2006. Fishery changes during reoligotrophication in 11 peri-alpine Swiss and French lakes over the past 30 years. Acta Oecol 30: 161-167.

Girard M. 2018. Comparaison jour - nuit de l'analyse hydroacoustique des peuplements piscicoles lacustres. Master2 Patrimoine naturel et biodiversité. Univ. Rennes 1.36 p.

Gliwicz M, Slon J, Szynkarczyk I. 2006. Trading safety for food: evidence from gut contents in roach and bleak captured at different distances offshore from their daytime littoral refuge. Freshw Biol 51 :823-839.

Godlewska M. 2002. The effect of fish migration patterns on the hydroacoustical estimates of fish stocks. Acta Acust United Ac 88: 4.

Godlewska M, Colon M, Jóźwik A, Guillard J. 2011. How pulse lengths impact fish stock estimations during hydroacoustic measurements at $70 \mathrm{kHz}$. Aquat Living Resour 24: 71-78.

Godlewska M, Izydorczyk K, Kaczkowski Z, Józwik A, Długoszewski B, Ye S, Lian Y, Guillard J. 2016. Do fish and blue-green algae blooms coexist in space and time? Fish Res 173: 93-100.

Guillard J, Lebourges-Dhaussy A, Brehmer P. 2004. Simultaneous Sv and TS measurements on Young-of-the-Year (YOY) freshwater fish using three frequencies. ICES J Mar Sci 61: 267-273.

Guillard J, Perga ME, Colon M, Angeli N. 2006. Hydroacoustic assessment of young-of-year perch. Perca fluviatilis population dynamics in an oligotrophic lake (Lake Annecy. France). Fish Manag Ecol 13: 319-327.

Guillard J, Brehmer P, Colon M, Guennégan Y. 2006. Three dimensional characteristics of young-of-year pelagic fish schools in lake. Aquat Living Res 19: 115-122.
Guillard J, Vergés C. 2007. The repeatability of fish biomass and size distribution estimates obtained by hydroacoustic surveys using various survey designs and statistical analyses. Inter Rev Hydrobiol 92: 605-617.

Guo AH, Yuan JL, Chu TJ, Lian QP. 2019. Hydroacoustic assessment of fish resources in three reservoirs : the effects of different management strategies on fish density. biomass and size. Fish Res 215: 90-96.

Hölker F, Dörner H, Schulze T, Haertel-Borer SS, Peacor SD, Mehner T. 2007. Species-specific responses of planktivorous fish to the introduction of a new piscivore: implications for prey fitness. Freshw Biol 52: 1793-1806.

Jacobsen L, Berg S, Jepsen N, Skov C. 2004. Does roach behaviour differ between shallow lakes of different environmental state? $J$ Fish Biol 65: 135-147.

Kahilainen K, Malinen T, Tuomaala A, Lehtonen H. 2004. Diel and seasonal habitat and food segregation of three sympatric Coregonus lavaretus forms in a subarctic lake. J Fish Biol 64: 418-434.

Kubečka J, Hohausová E, Matěna J, Peterka J, Amarasinghe US, Bonar SA, Winfield IJ. 2009. The true picture of a lake or reservoir fish stock: a review of needs and progress. Fish Res 96: 1-5.

Love RH. 1971. Dorsal-aspect target strength of an individual fish. $J$ Acous Soc Am 49: 816-823.

Luecke C, Wurtsbaugh WA. 1993. Effects of moonlight and daylight on hydroacoustic estimates of pelagic fish abundance. Trans Am Fish Soc 122: 112-120.

MacLennan DN, Fernandes PG, Dalen J. 2002. A consistent approach to definitions and symbols in fisheries hydroacoustics. ICES J Mar Sci 59: 365-369.

MacNamara R, Glover D, Garvey J, Bouska W, Irons K. 2016. Bigheaded carps (Hypophthalmichthys spp.) at the edge of their invaded range: using hydroacoustics to assess population parameters and the efficacy of harvest as a control strategy in a large North American river. Biol Invasions 18: 3293-3307.

Masson S, Angeli N, Guillard J, Pinel-Alloul B. 2001. Diel vertical and horizontal distribution of crustacean zooplankton and young of the year fish in a sub-alpine lake: an approach based on high frequency sampling. J Plankt Res 23: 1041-1060.

Matthews WJ. 2012. Patterns in freshwater fish ecology. Edit Kluwer Academic Publishers. 756 p.

Mehner T, Busch S, Helland IP, Emmrich M, Freyhof J. 2010. Temperature-related nocturnal vertical segregation of coexisting coregonids: Nocturnal segregation of coregonids. Ecol Fresh Fish 19: 408-419.

Mehner T. 2012. Diel vertical migration of freshwater fishes proximate triggers, ultimate causes and research perspectives: Diel vertical migration in freshwater fishes. Freshw Biol 57: 1342-1359.

Mouget A, Goulon C, Axenrot T, Balk H, Lebourges-Dhaussy A, Godlewska M, Guillard J. 2019. Including $38 \mathrm{kHz}$ in the standardisation protocol for hydroacoustic fish surveys in temperate lakes. Remote Sens Ecol Conserv 5: 332-345.

Morrissey-McCaffrey E, Rocks K, Kelly FL, Kelly-Quinn M. 2018. Effects of differing ground-truth data transect design and statistical analysis on the repeatability of hydroacoustic assessments of pollan Coregonus autumnalis pollan. Fish Manag Ecol 25: 304-318.

Parker-Stetter SL, Rudstam LG, Sullivan PJ, Warner DM. 2009. Standard operating procedures for fisheries hydroacoustic surveys in the Great Lakes. Great Lakes Fishery Commission Special Publication 9: 165. 
Périat G. 2012. Etude du peuplement pisciaire du Lac de Morat. Eawag. 47.

Périat G, Vonlanthen P. 2013. Etude du peuplement pisciaire du Lac de Neuchâtel. Eawag. 48.

Persson L, Eklöv P. 1995. Prey refuges affecting interactions between piscivorous perch and juvenile perch and roach. Ecology 76: 70-81.

Pollom RA, Rose GA. 2016. A global review of the spatial. taxonomic. and temporal scope of freshwater fisheries hydroacoustics research. Environ Rev 24: 333-347.

Probst WN, Thomas G, Eckmann R. 2009. Hydroacoustic observations of surface shoaling behaviour of young-of-the-year perch Perca fluviatilis (Linnaeus, 1758) with a towed upwardfacing transducer. Fish Res 96: 133-138.

R Core Team. 2014. R: A language and environment for statistical computing. Vienna: R Foundation for Statistical Computing. Austria. http://www.R-project.org/.

Ríha M, Ricard D, Vašek M, Prchalová M, Mrkvička T, Juza T, Kubečka J. 2014. Patterns in diel habitat use of fish covering the littoral and pelagic zones in a reservoir. Hydrobiology 747: $111-131$.

Rudstam LG, Jech JM, Parker-Stetter SL, Horne JK, Sullivan PJ, Mason DM. 2012. Fisheries hydroacoustics, in: A.V. Zale, D.L. Parrish, T.M. Sutton (eds.), Fisheries Techniques (3rd edn.) Bethesda, Maryland: American Fisheries Society, pp. 40.

Sajdlová Z, Frouzová J, Draštík V, Juza T, Peterka J, Prchalová M, Čech M. 2018. Are diel vertical migrations of European perch (Perca fluviatilis L.) early juveniles under direct control of light intensity? Evidence from a large field experiment. Freshw Biol 63: $473-482$.

Sawada K, Furusawa M, Williamson N. 1993. Condition for the precise measurement of fish target strength in situ. Fish Sci 20: 73-79.

Shaw E. 1962. The schooling of fishes. Scient Am 206:128-141.

Simmonds J, MacLennan DN. 2005. Fisheries Acoustics: Theory and Practice, 2nd edn. Fisheries Series. Oxford: Blackwell Publishing.
Snickars M, Sandström A, Mattila J. 2004. Antipredator behaviour of $0+$ year Perca fluviatilis: effect of vegetation density and turbidity. $J$ Fish Biol 65: 1604-1613.

Swales S. 2006. A review of factors affecting the distribution and abundance of Rainbow Trout (Oncorhynchus mykiss Walbaum) in lake and reservoir systems. Lake Reser Manag 22: 167-178.

Tessier A, Cottet M, Kue K, Chanudet V, Descloux S, Guillard J. 2020. Low input to fisheries of offshore areas in a large tropical neo-reservoir in Lao PDR. Limnology 21: 73-86.

Vondracek B, Degan DJ. 1995. Among and within transect variability in estimates of Shad abundance made with hydroacoustics. North Am J Fish Manag 15: 933-939.

Vonlanthen P, Périat G. 2013. Artenvielfalt und zusammensetzung der fischpopulation im Brienzersee. Eawag. 44.

Warton DI, Wright IJ, Falster DS, Westoby M. 2006. Bivariate linefitting methods for allometry. Biol Rev 81: 259-291.

Warton DI, Duursma RA, Falster DS, Taskinen S. 2012. Smatr 3-an R package for estimation and inference about allometric lines. Meth Ecol Evol 3: 257-259.

Wheeland LJ, Rose GA. 2014. Acoustic measures of lake community size spectra. Can J Fish Aquat Sci 73: 557-564.

Wheeland LJ, Rose GA. 2015. Quantifying fish avoidance of small hydroacoustic survey vessels in boreal lakes and reservoirs. Ecol Freshw Fish 24: 67-76.

Ye S, Lian Y, Godlewska M, Liu J, Li Z. 2013. Day-night differences in hydroacoustic estimates of fish abundance and distribution in Lake Laojianghe. China. J Appl Ichthyol 29: 1423-1429.

Yule DL, Evrard LM, Cachera S, Colon M, Guillard J. 2013. Comparing two fish sampling standards over time: largely congruent results but with caveats. Freshw Biol 58: 2074-2088.

Zenone AM, Burkepile DE, Boswell KM. 2017. A comparison of diver vs. acoustic methodologies for surveying fishes in a shallow water coral reef ecosystem. Fish Res 189: 62-66.

Cite this article as: Girard M, Goulon C, Tessier A, Vonlanthen P, Guillard J. 2020. Comparisons of day-time and night-time hydroacoustic surveys in temperate lakes. Aquat. Living Resour. 33: 9 